\title{
Numerical analysis of influence of streamline rudder on screw propeller efficiency
}

\author{
Tomasz Abramowski, Ph. D. \\ Jakub Handke, M. Sc. \\ Tadeusz Szelangiewicz, Prof. \\ West Pomeranian University of Technology, Szczecin
}

\begin{abstract}
During designing the ship its designer tends to obtain as high as possible efficiency of ship propulsion system. To this end on certain ships additional elements such as: nozzles, half-nozzles or suitably profiled fins attached to underwater part of ship's hull before screw propeller, are applied (sometimes they are intended for the mitigating of vibration resulting from operation of screw propeller). Another device which affects operation of screw propeller is streamline rudder capable of improving its efficiency (most of the transport ships is fitted with single screw propeller and streamline rudder placed behind it). In this paper the influence of streamline rudder on screw propeller efficiency has been examined with the use of numerical methods of fluid dynamics (CFD). The obtained results indicate a very favourable influence of the rudder on screw propeller efficiency. Research in this area is continued and its results concerning impact of particular geometrical parameters of rudder on screw propeller efficiency, will be presented in the future.
\end{abstract}

Keywords: Streamline rudder, improvement of screw propeller efficiency, computational fluid dynamics (CFD)

\section{INTRODUCTION}

During ship's design process one of the most important tasks is a design of its propulsion system which should ensure reaching the assumed service speed by the designed ship at its as high as possible propulsion efficiency. The crucial element of ship propulsion system is a screw propeller whose efficiency is decisive of overall propulsion efficiency. Geometry of screw propeller decides on its efficiency, hence it should be optimum one in assumed design conditions, i.e. screw propeller should develop demanded thrust at an assumed ship's service speed. Apart from the optimum design, screw propeller efficiency can be improved by using various additional devices such as: nozzles, half-nozzles, or suitably profiled fins attached to underwater part of ship's hull before screw propeller [5] (sometimes they are intended for the mitigating of hull plating vibration resulting from screw propeller operation). The additional devices are aimed at the improving of distribution (direction and velocity) of water stream flowing from around the hull towards the screw propeller. The devices produce a positive effect only in strictly defined conditions. As results from practice, they are applied very rarely.

Another device which influences screw propeller operation is a streamline rudder capable of improving its efficiency. Majority of transport ships is fitted with single screw propeller and streamline rudder placed behind it. Therefore it seems purposeful to examine which way and in which conditions streamline rudder affects screw propeller operation, and how much screw propeller efficiency can be increased.

\section{SCREW PROPELLER - STREAMLINE RUDDER SYSTEM}

The screw propeller - streamline rudder system is exemplified in Fig. 1.

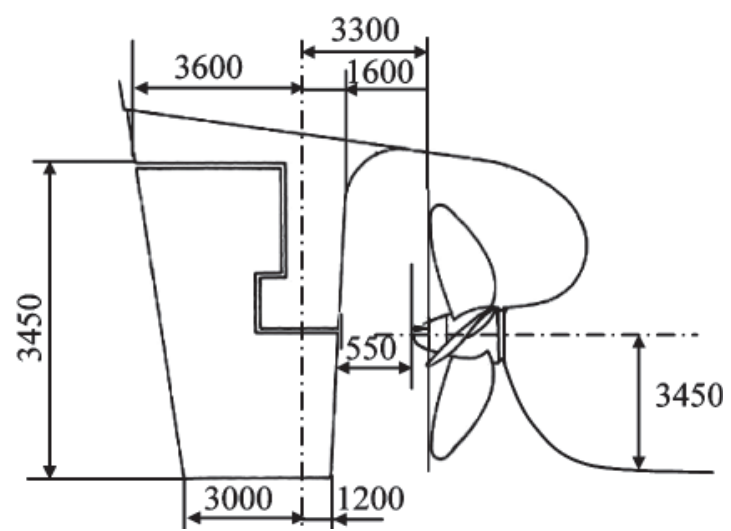

Fig. 1. The semi-spade rudder behind the screw propeller of B 573 ship [8]. (All the dimensions given in $\mathrm{mm}$ )

A few dozen years ago already it has been observed that a blade rudder of airfoil profile not only improves ship's manoeuvrability but also increases screw propeller efficiency and - in consequence - overall propulsion efficiency of ship [6]. The improvement of screw propeller efficiency results from the following reasons: 
- part straightening the flow behind the propeller (which leads to lowering the induced circumferential velocity)

- a more favourable distribution of water pressure behind the propeller and reduction of vortices flowing downstream from the propeller, mainly from its boss.

However apart from knowledge of the facts there is a lack of results of systematic investigations, e.g. model tests, and in the subject-matter literature only a general information can be found, that does not provide any basis to state which way geometrical features of streamline rudder affect screw propeller efficiency and how large increase of the efficiency would be possible. Yet the application of numerical methods of computational fluid dynamics (CFD) to modelling water flow around propeller and rudder has made it possible to assess qantitively and qualitively influence of rudder on screw propeller efficiency. Most publications in which results obtained by means of CFD methods have been presented, deal mainly with influence of screw propeller on ruddder or with investigation of flow around the hull, propeller and rudder [1, 2, 3, 4 and 7]. In this paper preliminary results of numerical investigations concerning influence of rudder on screw propeller efficiency, are presented.

\section{SCOPE OF THE INVESTIGATIONS}

Within the frame of the conducted research project a numerical analysis of flow around screw propeller was performed by using Fluent system to determine the thrust coefficient $\mathrm{Kt}$ and torque coeffcient $\mathrm{Kq}$ as well as screw propeller efficiency $\eta_{0}$ for:

- a free propeller

- a screw propeller accompanied with a rudder of HSVAMP7320 profile in the position of no deflection

- for a screw propeller accompanied with a rudder of HSVAMP73-20 profile in the position of $15^{\circ}$ deflection.

The investigations were performed for the hull of a B573 ship (built by Stocznia Szczecinska), its screw propeller and streamline rudder (Fig. 1).

As results of model tests on rudder / propeller interaction for the B 573 ship have been lacking, the obtained computational results were compared, only at the advance coefficient $J=0.70$, with the values calculated on the basis of the propulsion prediction for free screw propeller [8].

Geometrical parameters of the screw propeller of $B 573$ ship (Fig. 1) [9]:

$\begin{array}{lll}\text { Diameter } & \mathrm{D} & 5900 \mathrm{~mm} \\ \text { Pitch ratio } & \mathrm{P} / \mathrm{D} & 0.739 \\ \text { Expanded area ratio } & \mathrm{A}_{\mathrm{E}} / \mathrm{A}_{0} & 0.578 \\ \text { Number of blades } & \mathrm{Z} & 4\end{array}$

Geometrical parameters of the rudder of B 573 ship (Fig. 1) [8]:

The rudder was designed on the basis of HSVAMP73-20 profile. Its contour and size are in compliance with the rudder installed on B 573 ship.

The computational model of the rudder is shown in Fig. 2, and that of the screw propeller - in Fig. 3.

The computation domain consisted of three co-axial cylinders (Fig. 4). The screw propeller was placed inside the small cylinder put inside the fore large cylinder. Rear faces of both the cylinders were located in one common plane and adhered the fore face of the rear cylinder. Such arrangement makes it possible to apply the mesh for free- propeller calculations by using the sliding mesh method (the small cylinder is a rotating element and the large cylinders are motionless). For the free-propeller calculations no physical element is placed in the rear cylinder. For the calculations of propeller and rudder together in the rear cylinder is placed the rudder model either with or without deflection, respective of a modeled case.

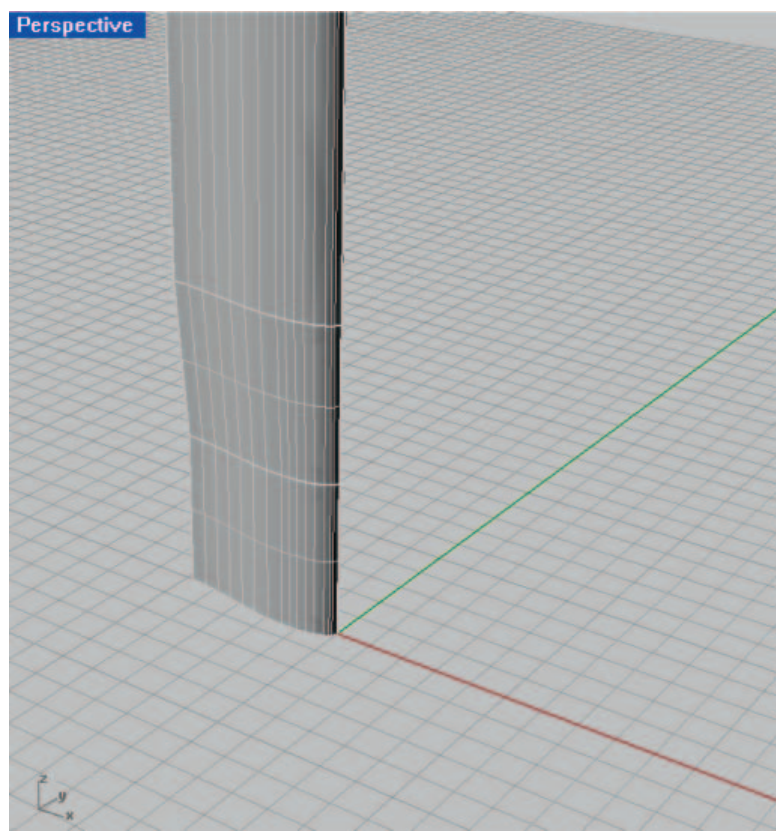

Fig. 2. Computational model of the rudder without any deflection

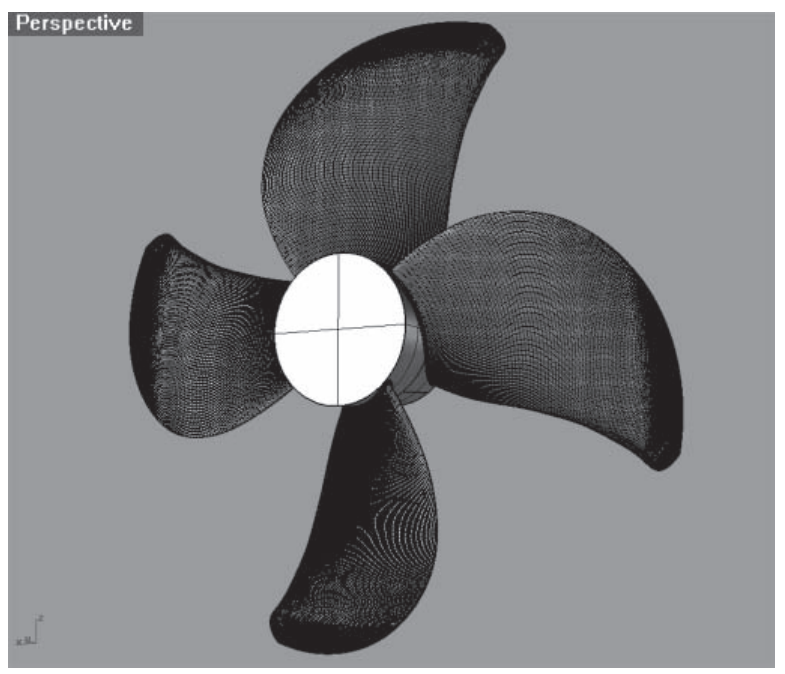

Fig. 3. Computational model of the screw propeller

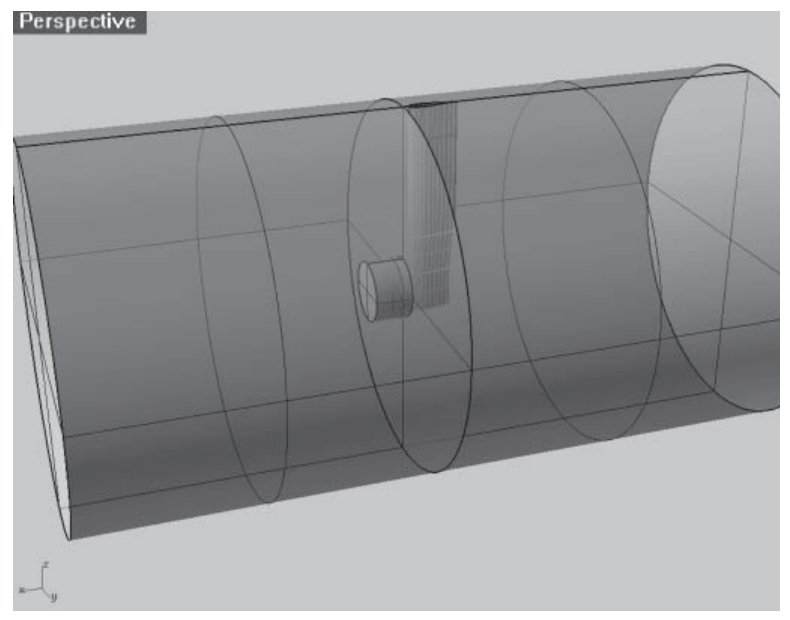

Fig. 4. Computation domain for the set of screw propeller and rudder 


\section{RESULTS OF THE NUMERICAL CALCULATIONS}

In advance of the actual calculations of rudder influence on screw propeller efficiency, the following has been calculated:

- Hydrodynamic characteristics of the screw propeller model, which were compared with results of experimental model tests. The propeller model geometry acc. P 355 storage propeller and results of its model tests are contained in the report [8].

Description of the numerical calculations of the hydrodynamic characteristics and their results are presented in [10].

$6.09 \mathrm{e}+04$
$5.23 \mathrm{e}+04$
$4.37 \mathrm{e}+04$
$3.52 \mathrm{e}+04$
$2.66 \mathrm{e}+04$
$1.80 \mathrm{e}+04$
$9.45 \mathrm{e}+03$
$8.80 \mathrm{e}+02$
$-7.69 \mathrm{e}+03$
$-1.63 \mathrm{e}+04$
$-2.48 \mathrm{e}+04$
$-3.34 \mathrm{e}+04$
$-4.20 \mathrm{e}+04$
$-5.06 \mathrm{e}+04$
$-5.91 \mathrm{e}+04$
$-6.77 \mathrm{e}+04$
$-7.63 \mathrm{e}+04$
$-8.49 \mathrm{e}+04$
$-9.34 \mathrm{e}+04$
$-1.02 \mathrm{e}+05$
$.1 .11 \mathrm{e}+05$

\section{Drag face of propeller}

\section{Driving face of propeller}

$\left.\begin{array}{l}6.09 \mathrm{e}+04 \\ 5.23 \mathrm{e}+04 \\ 4.37 \mathrm{e}+04 \\ 3.52 \mathrm{e}+04 \\ 2.66 \mathrm{e}+04 \\ 1.80 \mathrm{e}+04 \\ 9.45 \mathrm{e}+03 \\ 8.80 \mathrm{e}+02 \\ -7.69 \mathrm{e}+03 \\ -1.63 \mathrm{e}+04 \\ -2.48 \mathrm{e}+04 \\ -3.34 \mathrm{e}+04 \\ -4.20 \mathrm{e}+04 \\ -5.06 \mathrm{e}+04 \\ -5.91 \mathrm{e}+04 \\ -6.77 \mathrm{e}+04 \\ -7.63 \mathrm{e}+04 \\ -8.49 \mathrm{e}+04 \\ -9.34 \mathrm{e}+04 \\ -1.02 \mathrm{e}+05 \\ -1.11 \mathrm{e}+05\end{array}\right]$
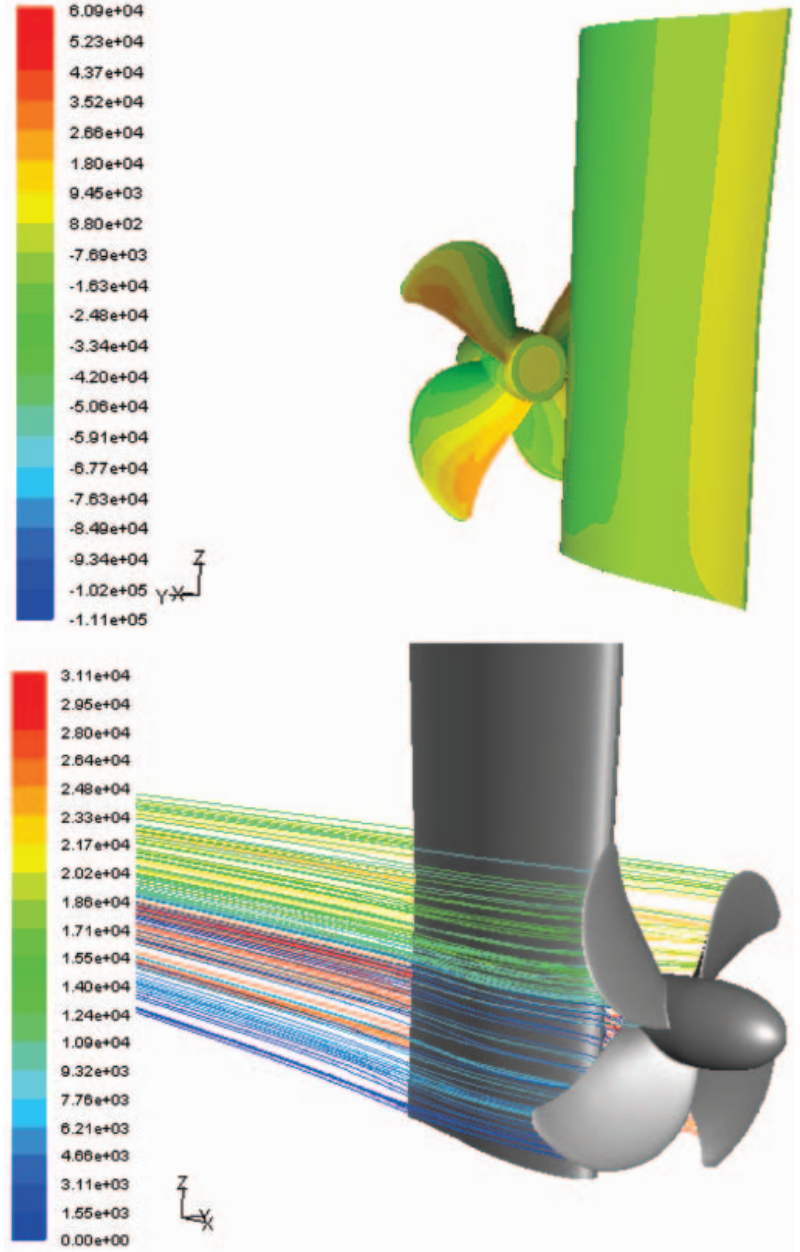

Fig. 5. Pressure distribution and streamlines for the set of propeller and rudder without any deflection, the advance ratio $J=0.7$

- Hydrodynamic characteristics of the streamline rudder of B 573 ship, (Fig. 1). Results of numerical calculations of the characteristics are presented in [11].

The actual numerical calculations of screw propeller efficiency with accounting for impact of ruddder,were then performed. They were carried out for the real dimensions of the propeller and rudder installed on B 573 ship, Fig.1.

In Fig. 5 an example pressure distribution and streamlines for both the propeller and rudder without any deflection is presented, and in Fig. 6 - for both the propeller and the rudder deflected by $15^{\circ}$ (The complete set of pressure and velocity distributions as well as streamlines is given in [12]).

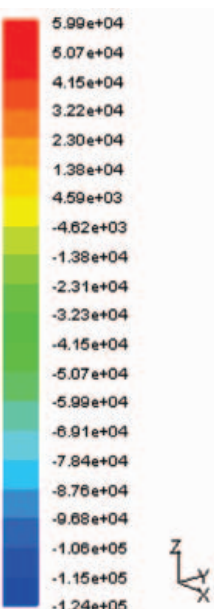

Drag face of propeller

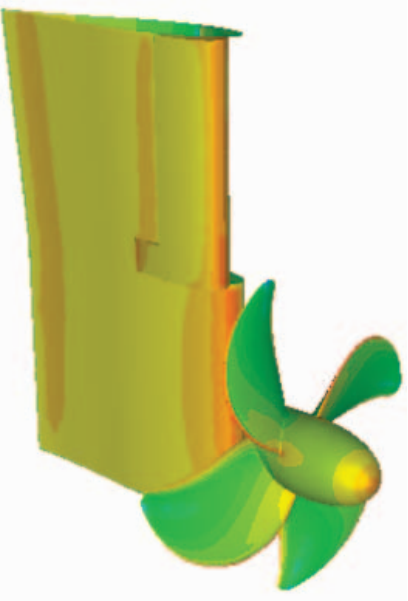

Driving face of propeller

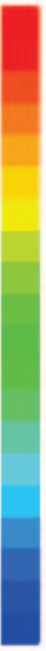

$5.99 \mathrm{e}+04$ $5.07 \mathrm{e}+04$ 4. $15 \mathrm{e}+04$ $3.22 \mathrm{e}+04$ $2.30 \mathrm{e}+04$ $1.38 \mathrm{e}+04$ $4.59 \mathrm{e}+03$ $.4 .62 \mathrm{e}+03$ $-1.38 \mathrm{e}+04$ $-2.31 \mathrm{e}+04$ $-3.23 \mathrm{e}+04$ $-4.15 \mathrm{e}+04$ $-5.07 \mathrm{e}+04$ $-5.99 \mathrm{e}+04$ $-6.91 \mathrm{e}+04$ $.7 .84 \mathrm{e}+04$ $-8.76 \mathrm{e}+04$ $.9 .68 \mathrm{e}+04$ $-1.06 \mathrm{e}+05$

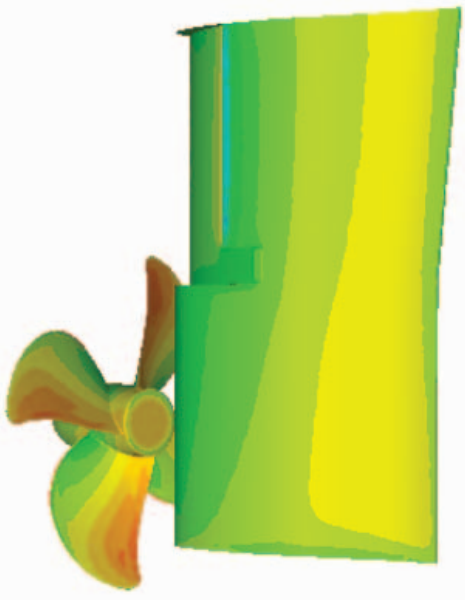

$.1 .24 \mathrm{e}+05$

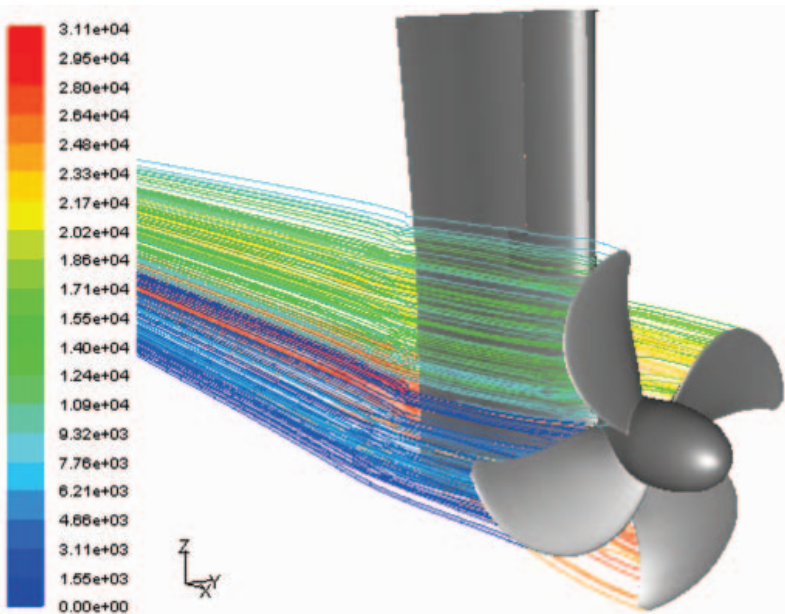

Fig. 6. Pressure distribution and streamlines for the set of propeller and rudder deflected by $15^{\circ}$, the advance ratio $J=0.7$ 
Tab. 1. Data and results of the analysis performed by using the Fluent system.

\section{Screw propeller without rudder}

\begin{tabular}{|c|c|c|c|c|c|c|c|c|c|c|}
\hline No. & $\mathrm{J}[-]$ & $\mathrm{D}[\mathrm{m}]$ & $\mathrm{n}[1 / \mathrm{s}]$ & $\mathrm{V}[\mathrm{m} / \mathrm{s}]$ & $\mathrm{T}[\mathrm{N}]$ & $\mathrm{Kt}[-]$ & $\mathrm{Q}[\mathrm{Nm}]$ & $10 \mathrm{Kq}[-]$ & $\rho\left[\mathrm{t} / \mathrm{m}^{3}\right]$ & $\eta_{0}[-]$ \\
\hline 1 & 0.1 & 5.9 & 1.5 & 0.885 & 1624159 & 0.596514 & 948528.9 & 0.59046 & 998.66 & 0.160868 \\
\hline 2 & 0.2 & 5.9 & 1.5 & 1.77 & 1365931 & 0.501673 & 839757.7 & 0.52275 & 998.66 & 0.305631 \\
\hline 3 & 0.3 & 5.9 & 1.5 & 2.655 & 1122907 & 0.412416 & 722395.3 & 0.449691 & 998.66 & 0.438109 \\
\hline 4 & 0.4 & 5.9 & 1.5 & 3.54 & 924202.1 & 0.339437 & 623854.7 & 0.38835 & 998.66 & 0.556719 \\
\hline 5 & 0.5 & 5.9 & 1.5 & 4.425 & 720384.5 & 0.264579 & 518421.4 & 0.322718 & 998.66 & 0.652745 \\
\hline 6 & 0.6 & 5.9 & 1.5 & 5.31 & 517910.9 & 0.190216 & 405355.8 & 0.252334 & 998.66 & 0.720215 \\
\hline 7 & 0.7 & 5.9 & 1.5 & 6.195 & 281523.2 & 0.103397 & 281425.6 & 0.175188 & 998.66 & 0.657871 \\
\hline 8 & 0.8 & 5.9 & 1.5 & 7.08 & 51307.51 & 0.018844 & 146254.1 & 0.091043 & 998.66 & 0.263667 \\
\hline \multicolumn{11}{|c|}{ Screw propeller + rudder without deflection } \\
\hline No. & $\mathrm{J}[-]$ & $\mathrm{D}[\mathrm{m}]$ & $\mathrm{n}[1 / \mathrm{s}]$ & $\mathrm{V}[\mathrm{m} / \mathrm{s}]$ & $\mathrm{T}[\mathrm{N}]$ & $\mathrm{Kt}[-]$ & $\mathrm{Q}[\mathrm{Nm}]$ & $10 \mathrm{Kq}[-]$ & $\rho\left[\mathrm{t} / \mathrm{m}^{3}\right]$ & $\eta_{0}[-]$ \\
\hline 1 & 0.1 & 5.9 & 1.5 & 0.885 & 1529143 & 0.561616 & 930528 & 0.579254 & 998.66 & 0.154387 \\
\hline 2 & 0.2 & 5.9 & 1.5 & 1.77 & 1295804 & 0.475917 & 802417.5 & 0.499505 & 998.66 & 0.303432 \\
\hline 3 & 0.7 & 5.9 & 1.5 & 6.195 & 354941.1 & 0.130361 & 298832.2 & 0.186023 & 998.66 & 0.781123 \\
\hline \multicolumn{11}{|c|}{ Screw propeller + deflected rudder } \\
\hline No. & $\mathrm{J}[-]$ & $\mathrm{D}[\mathrm{m}]$ & $\mathrm{n}[1 / \mathrm{s}]$ & $\mathrm{V}[\mathrm{m} / \mathrm{s}]$ & $\mathrm{T}[\mathrm{N}]$ & $\mathrm{Kt}[-]$ & $\mathrm{Q}[\mathrm{Nm}]$ & $10 \mathrm{Kq}[-]$ & $\rho\left[\mathrm{t} / \mathrm{m}^{3}\right]$ & $\eta_{0}[-]$ \\
\hline 1 & 0.1 & 5.9 & 1.5 & 0.885 & 1618327 & 0.594372 & 950265.5 & 0.591541 & 998.66 & 0.159998 \\
\hline 2 & 0.2 & 5.9 & 1.5 & 1.77 & 1388741 & 0.51005 & 839860.6 & 0.522814 & 998.66 & 0.310697 \\
\hline 3 & 0.7 & 5.9 & 1.5 & 6.195 & 380906.1 & 0.139897 & 315136.1 & 0.196172 & 998.66 & 0.794896 \\
\hline
\end{tabular}

Results of the calculations of thrust, torque and efficiency of the propeller with accounting for the rudder, are presented in Tab. 1, and its hydrodynamic characteristics - in Fig. 7 through 10.

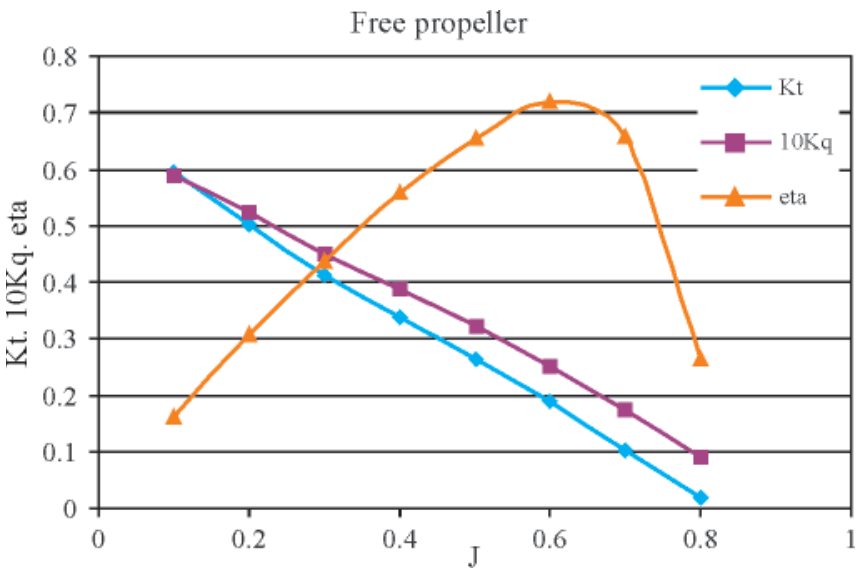

Fig. 7. Hydrodynamic characteristics of the free propeller without rudder

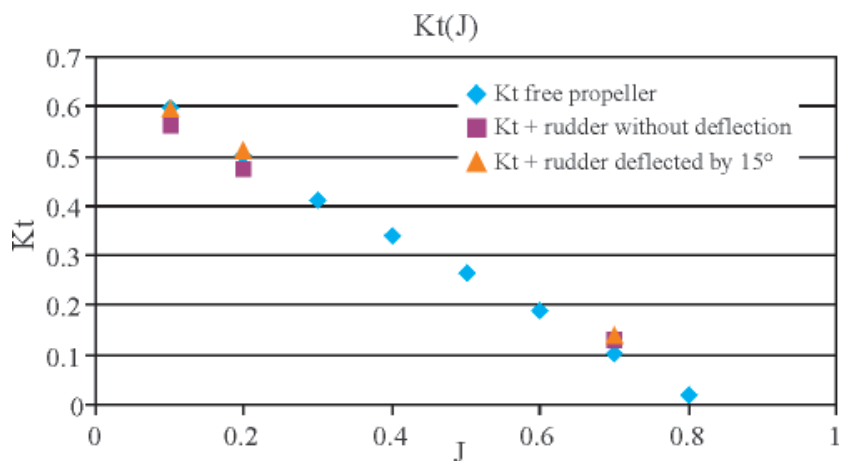

Fig. 8. The thrust coefficient $K_{T}$ for the free propeller, the set of the free propeller and rudder without deflection and that of the free propeller and rudder deflected by $15^{\circ}$

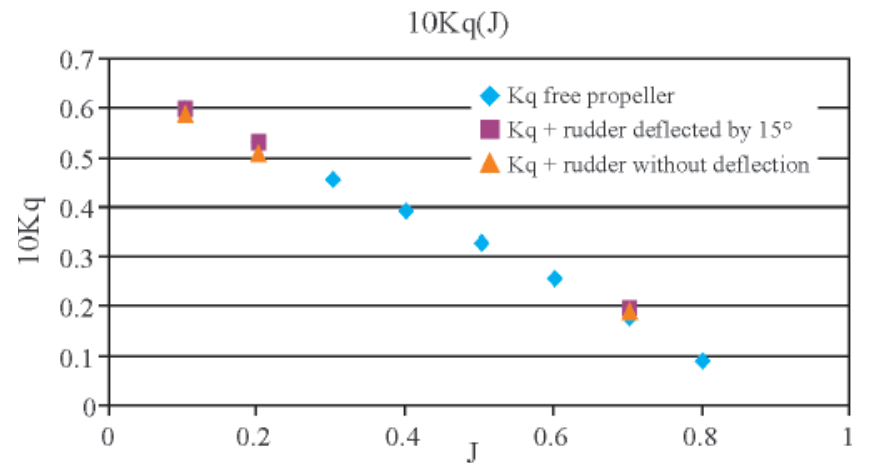

Fig. 9. The torque coefficient Kq for the free propeller, the set of the free propeller and rudder without deflection and that of the free propeller and rudder deflected by $15^{\circ}$ Efficiency $\eta_{0}$

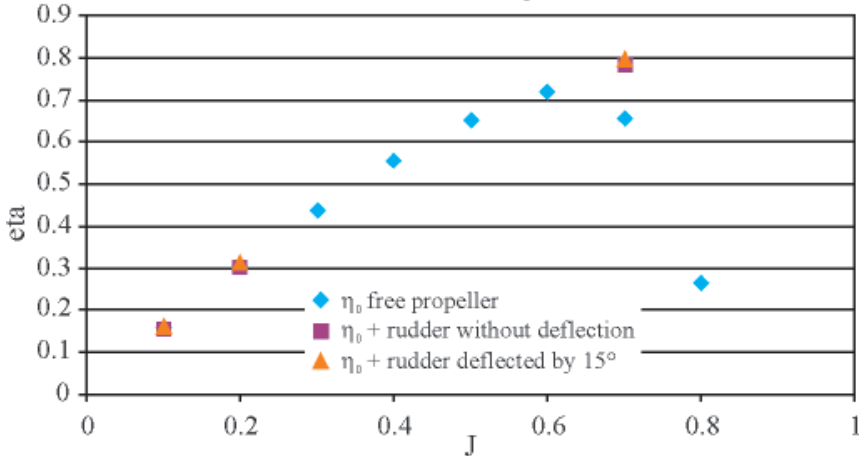

Fig. 10. The efficiency $\eta_{0}$ for the free propeller, the set of the free propeller and rudder without deflection and that of the free propeller and rudder deflected by $15^{\circ}$ 


\section{CONCLUSIONS}

As data concerning results of model tests are very scarce, to make comparison of the numerical analysis results with those of real model tests for free propeller is possible only for values corresponding with the advance ratio $\mathrm{J}=0.70$; relevant results of numerical calculations and model tests are compared in Tab. 2.

Tab. 2.

\begin{tabular}{|c|c|c|c|}
\hline & model tests & $\begin{array}{c}\text { numerical } \\
\text { analysis }\end{array}$ & model / analysis \\
\hline $\mathbf{T}$ & 314800 & 281523.2 & 1.11820269 \\
\hline $\mathbf{Q}$ & 228800 & 281425.59 & 0.81300354 \\
\hline $\boldsymbol{\eta}$ & 0.564 & 0.65787141 & 0.8573104 \\
\hline
\end{tabular}

The comparison of results for only one value of the advance ratio $\mathrm{J}$ does not allow to assess if the remaining results are correct or not, and does not provide information on correctness of run of the characteristics. However this is the only way of assessing the performed analysis in view of the lack of data.

Comparison of the efficiency, thrust and torque coefficients for free propeller, the set of propeller and rudder without deflection and that of propeller and rudder deflected by $15^{\circ}$, is performed in Tab. 3, 4 and 5.

Tab. 3.

\begin{tabular}{|c|c|c|c|c|}
\hline \multicolumn{5}{|c|}{ Efficiency $\boldsymbol{\eta}_{\mathbf{0}}$} \\
\hline No. & J & $\begin{array}{c}\text { Free } \\
\text { propeller }\end{array}$ & $\begin{array}{c}\text { Propeller }+ \\
\text { rudder without } \\
\text { deflection }\end{array}$ & $\begin{array}{c}\text { Propeller } \\
\text { + rudder } \\
\text { deflected } \\
\text { by 15 }\end{array}$ \\
\hline 1 & 0.1 & 0.160868285 & 0.154387068 & 0.159997698 \\
\hline 2 & 0.2 & 0.305630894 & 0.303431839 & 0.310696571 \\
\hline 3 & 0.7 & 0.65787141 & 0.781122746 & 0.794895671 \\
\hline
\end{tabular}

Tab. 4.

\begin{tabular}{|c|c|c|c|c|}
\hline \multicolumn{5}{|c|}{ Thrust coefficient $\mathbf{K}_{\mathrm{T}}$} \\
\hline No. & $\mathbf{J}$ & $\begin{array}{c}\text { Free } \\
\text { propeller }\end{array}$ & $\begin{array}{c}\text { Propeller }+ \\
\text { rudder without } \\
\text { deflection }\end{array}$ & $\begin{array}{c}\text { Propeller }+ \\
\text { rudder } \\
\text { deflected } \\
\text { by 15 }\end{array}$ \\
\hline 1 & 0.1 & 0.596513711 & 0.561616382 & 0.594371651 \\
\hline 2 & 0.2 & 0.501672932 & 0.47591672 & 0.510050409 \\
\hline 3 & 0.7 & 0.103396532 & 0.130361105 & 0.13989741 \\
\hline
\end{tabular}

Tab.5.

\begin{tabular}{|c|c|c|c|c|}
\hline \multicolumn{5}{|c|}{ Torque coefficient $K_{q}$} \\
\hline No. & $\mathbf{J}$ & $\begin{array}{c}\text { Free } \\
\text { propeller }\end{array}$ & $\begin{array}{c}\text { Propeller + } \\
\text { rudder without } \\
\text { deflection }\end{array}$ & $\begin{array}{c}\text { Propeller }+ \\
\text { rudder } \\
\text { deflected } \\
\text { by } 15^{\circ}\end{array}$ \\
\hline 1 & 0.1 & 0.059045983 & 0.057925422 & 0.05915408 \\
\hline 2 & 0.2 & 0.052274967 & 0.049950537 & 0.052281374 \\
\hline 3 & 0.7 & 0.01751876 & 0.018602322 & 0.019617241 \\
\hline
\end{tabular}

In numerical calculations an applied computational model, type and size of mesh, and quality of geometrical model of analysed propeller play a very important role. The applied computational model could differ from the real propeller because of very scarce data on propeller geometry, hence to assess a degree of similarity between model and real propeller is not possible. The qualitative analysis performed by means of CFD methods demonstrated that the working screw propeller accompanied with streamline rudder located behind it, is capable of developing a greater efficiency than the free propeller without rudder.

As a result of presently conducted investigations an impact of geometrical parameters of rudder on propeller efficiency will be determined.

\section{BIBLIOGRAPHY}

1. Simonsen D. C.: Rudder Propeller and Hull Interaction by $R A N S$. Doctoral thesis, Technical University of Denmark, Lyngby 2000

2. Bertram V., Heinemann B., House L.: Practical Ship Hydrodynamics. Jordan Hill Oxford OX2 8DP, 2000

3. El Moctar O.M. El., Bertram V.: Selected Topics of CFD for Ship Manoeuvring. INSEAN/Rome, 14-18 May 2001

4. Natarajan S.: Computational Modeling of Rudder Cavitation and Propeller/Rudder Interaction. The University of Texas at Austin, August 2003

5. Schneekluth H., Bertram V.: Ship Design for Efficiency and Economy. Butterworth Heinemann, Oxford 2004

6. Kobyliński L.: Ship propellers (in Polish). Wydawnictwo Komunikacyjne (Transportation publishers), Warsaw 1955

7. Koronowicz T., Waberska G., Krzemianowska Z.: Influence of rudder on velocity field in waterstream behind the hull (in Polish). Institute of Fluid Flow Machinery, Polish Academy of Sciences, Publ. No. 4493/4, Gdańsk 2004

8. Syrocki W.: Ship B 573 - Results of the Model Tests (in Polish). Ship Design and Research Centre, Technical Report No. RH-96/ T-023A, Gdańsk 1995

9. Syrocki W.: Ship B 573 - Final Design of Propeller (in Polish). Ship Design and Research Centre, Technical Report No.RH-95/ T-115A, Gdańsk 1995

10.Abramowski T., Żelazny K., Szelangiewicz T.: Numerical analysis of influence of ship hull modification on resistance and propulsion characteristics, Part III: Influence of the modification on screw propeller efficiency. To be published in PMR No $1 / 2010$

11.Abramowski T., Szelangiewicz T.: Numerical analysis of selected elements on effectiveness of streamline rudder. To be published in PMR No 1/2010

12.Szelangiewicz T.: Numerical investigations of rudder/propeller/ ship stern interaction aimed at improving transport ship's propulsion and manoeuvrability qualities (in Polish). Final report of the R\&D project No. R 10008 01, Szczecin 2009.

\section{CONTACT WITH THE AUTHORS}

Tomasz Abramowski, Ph. D. Jakub Handke, M. Sc.

Tadeusz Szelangiewicz, Prof.

West Pomeranian University of Technology, Szczecin

Faculty of Marine Technology

Al. Piastów 41

71-065 Szczecin, POLAND

e-mail: tadeusz.szelangiewicz@ps.pl 